\title{
DEVELOPING A METHODOLOGY FOR TESTING AND PRELIMINARY DETERMINATION OF THE PRESENCE OF LEGIONELLA SPP. AND LEGIONELLA PMEUMOPHILA IN ENVIRONMENTAL WATER SAMPLES BY IMMUNOMAGNETIC SEPARATION COMBINED WITH FLOW CYTOMETRY
}

\author{
Zbigniew Dabrowiecki 1), Małgorzata Dąbrowiecka 1), Romuald Olszański ${ }^{1)}$, Piotr Siermontowski ${ }^{1,2}$ )
}

1) Maritime \& Hyperbaric Medicine Department, Military Institute of Medicine, Gdynia, Poland

2) Department of Submarine Work Technology, Naval Academy, Gdynia, Poland

\section{ABSTRACT}

In the event of an epidemic of Legionnaires' disease, prompt and unambiguous identification of the source of infection and immediate undertaking of repair actions is a necessary condition to limit and minimise the effects of the developing epidemic. In the classical method for determining the level of Legionella bacteria in water samples, the effectiveness of the reparative action (increase of the water temperature in the water supply system to $60^{\circ} \mathrm{C}$, additional chlorination) can only be confirmed after 14 days!!! Only by using the IMMS\&FCM method can Legionella's determination time be reduced to 2-4 hours, which is the most important factor in limiting the development of an epidemic.

Keywords: Legionella spp., Legionnaires' Disease, immunomagnetic separation, flow cytometry, hot water distribution systems, public utility buildings, ships.

\section{ARTICLE INFO}

PolHypRes 2019 Vol. 68 Issue 3 pp. $71-92$

ISSN: 1734-7009 elSSN: 2084-0535

DOI: 10.2478/phr-2019-0013

Pages: 22, figures: 5 , tables: 5

Original article

page www of the periodical: www.phr.net.pl

Submission date: 22.02.2019 r.

Acceptance for print: 23.07.2019 r.

Publisher

Polish Hyperbaric Medicine and Technology Society 


\section{INTRODUCTION}

\section{LEGIONELLA BACTERIA - MAIN MICROBIOLOGICAL HAZARDS TRANSMITTED BY SERVICE WATER IN THE FACILITIES AND VESSELS OF THE NAVY OF THE REPUBLIC OF POLAND}

Legionella is a commonly occurring bacterium in the aquatic environment. Particularly dangerous is Legionella pneumophila, one of more than thirty species of this bacterium.

All Legionella bacteria develop in puddles of dirty water, biofilm contained in water supply pipes, at the outlets of air conditioning systems. The cells of these bacteria were also found under shower strainers and in taps with running water.

At room temperature, Legionella pneumophila can survive more than 12 months in tap water. The habitat of these bacteria can be streams, ponds or even mud.
A legionella longbeachae strain has been identified in compost and soil in greenhouses with floral cultures.

In 2010, a report appeared about a new source of Legionella spp. infection which is particularly hazardous for professional drivers. This source was a suspension of water produced by the car windshield flushing system [1]. Legionella multiplies as an intracellular parasite (in amoebae), in the biofilm or in a free state in flowing water.

In aerosol form it can reach the human lungs causing severe pneumonia, legionellosis or a moderate respiratory infection called Pontiac fever.

Epidemics caused by Legionella pneumophila are characterised by high mortality (15-20\%), which can reach up to $50 \%$ in immunocompromised patients.

According to the GIDEON on-line portal, between 1999 and 2015 in Poland we observe a systematic increase in the detection of Legionella spp. bacteria in the environment.

Legionellosis in Poland.

\begin{tabular}{llllll}
\hline $\mathbf{1 9 9 9}$ & $\mathbf{2 0 0 3}$ & $\mathbf{2 0 0 4}$ & $\mathbf{2 0 0 5}$ & $\mathbf{2 0 0 6}$ & $\mathbf{2 0 0 7}$ \\
\hline 0 & 3 & 8 & 21 & 89 & 29 \\
\hline $\mathbf{2 0 0 8}$ & $\mathbf{2 0 0 9}$ & $\mathbf{2 0 1 0}$ & $\mathbf{2 0 1 1}$ & $\mathbf{2 0 1 2}$ & $\mathbf{2 0 1 3}$ \\
\hline 20 & 10 & 36 & 18 & 8 & 11 \\
\hline $\mathbf{2 0 1 4}$ & $\mathbf{2 0 1 5}$ & & & & \\
\hline 12 & 23 & & & & \\
\hline
\end{tabular}

In general, it can be said that the level above which there is a risk of infection for humans is:

$10^{4} \mathrm{cfu} / \mathrm{L}$ or $6.4 \times 10^{4}$ gu for Legionella spp $10^{2} \mathrm{cfu} / \mathrm{L}$ or $6.4 \times 10^{2} \mathrm{gu}$ for Legionella pneumophila

The Legionella spp. risk assessment is traditionally carried out by concentrating a water sample by centrifugation or filtration followed by selective multiplication. It is treated as a so-called "reference standard" and has many disadvantages, including the most important one, i.e. a long multiplication period of approximately 10 days. Such a long period of time, from the moment of sampling to the moment of obtaining the result, makes the classical method useless in a situation requiring rapid intervention and preventive action.

In addition, under certain, not so rare conditions such as oxidative or osmotic stress and low nutrient levels, Legionella bacteria may lose their ability to divide, while retaining the potential to return to the function of multiplication in favourable conditions.

These so-called 'dormant' Legionella cells (VBNC Legionella cells) pose a real threat to humans and are the main cause of the discrepancy in the classic and RT-PCR assay of Legionella bacteria.

The obligation to perform periodic tests for the presence of Legionella bacteria in water in public utility buildings is specified in the Regulation of the Minister of Health of 29 June 2007 on the quality of drinking water
(Journal of Laws No. 61, item 417).

In water samples taken by employees of the WSSE Gdańsk and samples taken by ZMMiH WIM staff in selected facilities of the Polish Navy, the Environmental Research Laboratory of ZMMiH WIM and the Microbiology Laboratory of the WSSE conducted tests for the presence of Legionella spp. using the classical method and RT-PCR technique using commercial sets manufactured by BioRad and Immogena $[2,3,4]$.

Simultaneously in all water samples the level of $L$. pneumophila SG1 was determined by IMS immunoseparation with flow cytometry (FCM) analysis.

The aim of this study was to develop a methodology for determining the presence of Legionella pneumophila bacteria in environmental samples using qPCR and IMS methods (magnetic immunoseparation).

\section{LEGIONELLA - TESTING METHODOLOGY BY IMMUNOSEPARATION AND FLOW CYTOMETRY}

The method of separation with the use of magnetic particles was invented by Professor John Ugelstad as early as in the 1970s. Today, immunoseparation techniques have revolutionised the methods of isolation of many biological substances and particles and have found a large number of applications in numerous scientific fields, for which methods of purification and separation are one of the most important 
and complex processes.

It is worth noting that research on this method is conducted with great intensity all over the world. Each year the number of applications is increasing and numerous technological studies are being developed, which significantly contribute to the development of the method, e.g. non-linear magnetophoretic separation, the advantage of which is the possibility to use many pathogens for simultaneous separation with sensitivity up to a million times higher than solid phase immunological tests, now commonly used in diagnostics.

Many advantages of the immunoseparation method have led to significant development of the method, improvement of its efficiency and development of magnetic particles with immobilised antibodies of lower sedimentation degree, smaller size and very diverse composition. Financially attractive and highly efficient methods are critical factors in industrial biotechnology and biological routine diagnostic procedures. Biomagnetic isolation techniques have become extremely important and have been applied in many areas, such as genetic engineering, immunology and molecular diagnostics.

Magnetic particles with a core of magnetite and coated with specific antibodies are particles of very high stability, uniformity, unique paramagnetic properties, low interaction between themselves and high dispersion ability. They are a very good alternative to the currently widely used technology of nucleic acid purification on columns with different types of sorbents. Their application allows to significantly shorten the time and reduce the investment outlays associated with the costly implementation of the technological process such as cell separation or efficient nucleic acid extraction.

Rapid cell separation or nucleic acid purification is a key step in most molecular biology and diagnostic procedures. The main objective of this stage is to achieve high quality and purity of biological material, regardless of its source. Separation processes are the first step preceding any other molecular technique. Nowadays, the use of modern molecular techniques is a powerful weapon to analyse the architecture of genes and control their expression. The obtained material is used in other molecular techniques such as PCR polymerisation chain reaction, RTPCR, qPCR, genomic library construction, hybridisation, RFLP, ALFP, and preparation of microarrays for gene expression analysis.

The growing demand for immunoseparation methods and their market implementation is mainly due to the growing demand on the part of medicine and industrial biotechnology. Molecular tests are used in the analysis of cancer markers, diagnosis of bacterial diseases such as borreliosis and viral diseases such as hepatitis HCV, HBV or analysis of potential sources of contamination such as analysis of water samples [5].

The test material is usually samples of peripheral blood, animal and plant tissues, dried blood, sperm, saliva and blood stains from different animal species, mycelium fragments, and water samples. At present, it is difficult to imagine, inter alia, an investigation of disputed fatherhood or forensic medicine and criminology without the use of molecular techniques to study microscopic and biological traces found at the crime scene, which may provide evidence. There are many methods of extracting material from the sample, but the selection of the most appropriate one depends on the type of material analysed.

The choice of sample preparation method prior to analysis using molecular techniques is critical for the sensitivity of the analytical technique and is in most cases crucial for the success of the entire diagnostic process.

When selecting the appropriate method, a wide spectrum of application of the obtained isolates in further analytical processes should be taken into account. Different quality requirements mean that it is difficult to propose one common sample preparation technique for techniques based on genomic assays such as classic PCR, qPCR, LAMP Loop (Mediated Isothermal Amplification), CPA (Cross Primer Amplification) and proteomic - ELISA, immunochromatography (LF).

The existing analytical techniques, apart from the classical method (inoculation), are mostly based on nucleic acid extraction or proteomic analysis and are usually a combination of two or more of the following techniques: precipitation by solvent extraction, chromatography, centrifugation or affinity-based separation. Popular methods for genomic DNA determination of bacteria (PCR, qPCR) have been developed based on nucleic acid extraction by column chromatography. Specially prepared columns, with a sorbent or membrane, bind nucleic acids under conditions of high ionic strength. The application of the chromatographic technique allowed to significantly simplify and shorten the time of nucleic acids isolation in comparison to classical methods, especially the solvent extraction method.

The limitations of the method result from the fixed amount of sorbent in the chromatographic column (which remains unchanged), while increasing the efficiency of the isolation process involves the use of a much larger number of columns, or the purchase of a set version designed for a different scale with a larger amount of sorbent, which is an additional economic barrier, or extends the time required for preparation of material for analysis. Another limitation of the chromatographic method is the relatively high degree of DNA fragmentation, which may affect the analytical process itself. On sorbent columns, fragments of several dozen to several hundred thousand pairs of bases are usually obtained, which significantly hinders accurate quantitative measurement of nucleic acids. An additional limitation of the genomic DNA extraction technique is the impossibility of answering the question of whether living or dead cells have been extracted from the isolate. Therefore, using these methods, it is not possible to unequivocally answer the question of whether the material assessed is infectious. In addition, chromatographic techniques necessitate the use of special equipment, which also severely limits the ease with which the sample preparation process can be carried out. It is practically impossible to use chromatographic methods to test more than a few dozen samples at the same time.

When developing the test methodology at the sample preparation stage, efforts were made to consider all the criteria for evaluating the method and, at the final stage, to develop a fast and reliable diagnostic method that would also allow for full automation of the process.

While analysing the separation techniques we evaluated many parameters affecting the performance, sensitivity and specificity of the diagnostic process and the scalability of the method, the risk of contamination and the possibility of automation of the method.

High efficiency of the separation/isolation process, i.e. the number of bacteria cells, nucleic acid particles or protein antigen extracted per specified amount of the starting material to be analysed, ensures that the optimum sensitivity of the analytical method is achieved.

The sensitivity of the method is also a parameter 
that determines the minimum amount of material that can be used for isolation in order to obtain a measurable result or a positive result from the analytical method. This is particularly important for diagnostic tests, where the sensitivity of the diagnostic method may be decisive for the patient's survival. During the validation test, the parameter LOD - limit of detection of the analytical method - is determined.

The purity of the obtained nucleic acid or protein isolate largely determines the selection of other testing techniques and decisively affects the sensitivity and efficiency of the adopted testing method. Obtaining high purity of nucleic acids and proteins often determines the success and outcome of the entire diagnostic procedure.

The scalability of the method determines the possibility of increasing or decreasing the scale of the process in relation to the current need. The ability to obtain more or less isolate from a wide range of sample volumes makes it more versatile and cost-effective.

The risk of contamination is the risk of biological contamination of the sample during the process. Increased risk of contamination during the process eliminates the applicability of the method in molecular diagnostics.

\section{IMMUNOSEPARATION TECHNIQUES}

Taking into account the above criteria, the only method to be used in the analysis of water samples for the presence of Legionella pneumophila bacteria is the IMS technique - immunoseparation operating on the basis of magnetic particles coated with a fraction of immunoglobulin which naturally binds the surface antigens of Legionella pneumophila bacteria. The magnetic particles used in the development of the L. pneumophila test method were obtained from Rqmicro company (Switzerland).

Several aminosilane derivatives have been isolated, which can be successfully deposited on the surface of magnetite and used to prepare sorbents using the IMS technique as the basis for the attachment of immunoglobulin fractions specifically binding bacterial antigens, e.g. Legionella pneumophila.

The diameter of magnetic particles with immobilised fraction of IgG anti-Legionella pneumophila immunoglobulin proteins is calibrated at $\sim 100 \mathrm{~nm}$, so the magnetic field obtained on their basis is characterised by a very well-developed binding surface while maintaining very strong magnetic properties.

The obtained magnetic particles have been thoroughly examined with respect to their stability and the data obtained confirm their high suitability for achieving the assumed objective. The IMS immunoseparation technique enables a very rapid, efficient and specific binding of whole bacterial cells of Legionella pneumophila bacteria to the surface of the particles.

The Rqmicro kit - L. pneumophila SG1 manufactured on the basis of the above mentioned magnetic particles has been evaluated in connection with the current study.

\section{FLOW CYTOMETRY (FCM) [6]}

Flow cytometry, the first technique developed for single cell analysis, combines the flexibility and sensitivity of fluorescence technology with the speed and feasibility of data integration. It has become the gold standard in cellular analysis and is now used as an analytical tool in many areas of life sciences.

As cellular biology research develops, flow cytometry, due to its widespread use, has an increasing number of analytical applications. It offers several important opportunities for researchers and clinicians.

Firstly, it enables the analysis of cell populations on a cell-by-cell basis (one cell after another). This is a critical ability for today's researchers and clinicians, who are looking for very specific cells among the many found in the sample. This makes it possible to diagnose or monitor many biological processes that cause serious diseases or to monitor emerging biological hazards in samples of the examined cells.

Secondly, flow cytometry has a fundamental advantage - it is extremely fast. The speed of routine sample analysis can reach up to 10,000 cells per second an incredible improvement compared to historical methods of visual examination and cell counting. This technique makes it possible to simultaneously measure multiple parameters (so-called multiplexing) of individual cells.

Flow cytometry can be used to both sort and analyse cell populations. This is valuable because it facilitates analysis of the specific type of cells that are being searched for. As soon as the population of cells to be sorted is identified, a fluid stream containing the sample is redirected at high pressure through the fluid system into a single stream whereby the cells pass individually through the laser beam, where cell information is detected. If the cell corresponds to a specific parameter, the cytometer generates an electrical charge. As a result, the charged cell is deflected into a tube and sorted. The sorted cells can be cultured or tested by other tests. Uncharged droplets are directed to the waste container along with the stream. This process is fast and enables the analysis of approximately 20,000 cells per second.

Flow cytometers include three main systems fluid, optical and electronic. The fluid system passes a sample of whole cells (e.g. an IMS sample) through a flow chamber in such a way that the cells pass individually through a laser beam. Each cell passing through the beam scatters the light and may emit fluorescent light. These light signals are collected by the optical system and directed to various detectors. The signals received by the detectors are then converted into numerical values by the electronics. Results can be displayed on the screen or saved for future analysis using specially designed software. As each cell passes through the beam, its parameters (e.g. whether it is alive or dead) are measured and recorded. Typically, data are collected for at least 10,000 cells per sample.

Monoclonal antibodies are most commonly used to mark cells in cytometry, allowing researchers to "mark" specific cell populations. Simultaneous analysis of many cell populations and their functional parameters required the inclusion of fluorescence and multicolour staining into the technology. The result of this combination of technologies is a very effective system that can be used to monitor biological hazards. Its definite advantage is the possibility of analysing single cells and their subsequent grouping, e.g. into living and dead cells. 


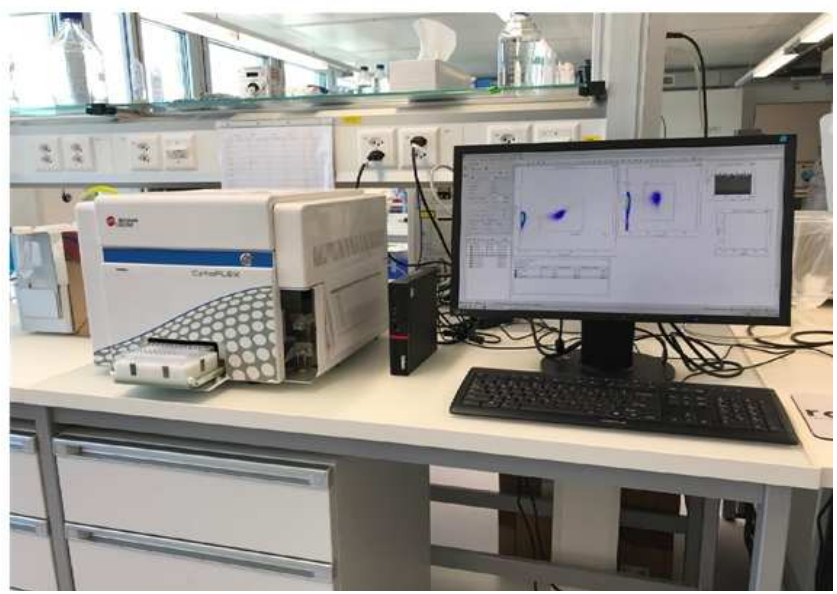

Fig. 1 Cytoflex flow cytometers with Laser: $488 \mathrm{~nm}$ multisampler (525/40 BP; 690/50 BP). Manufactured by Beckman Coulter, SN:AW27181.

\section{RESEARCH METHODOLOGY}

L. pneumophila (IMS) research methodology comprises four stages:

1. Concentration of the water sample by filtration and dissolution in a small amount of buffer (NR1).
2. Incubation - binding Legionella cells to magnetic particles (NR2).

3. Purification by means of the CellStream magnetic immunoseparator (NR3).

4. Quantitative sample analysis on flow cytometer and qPCR reaction device (NR4).

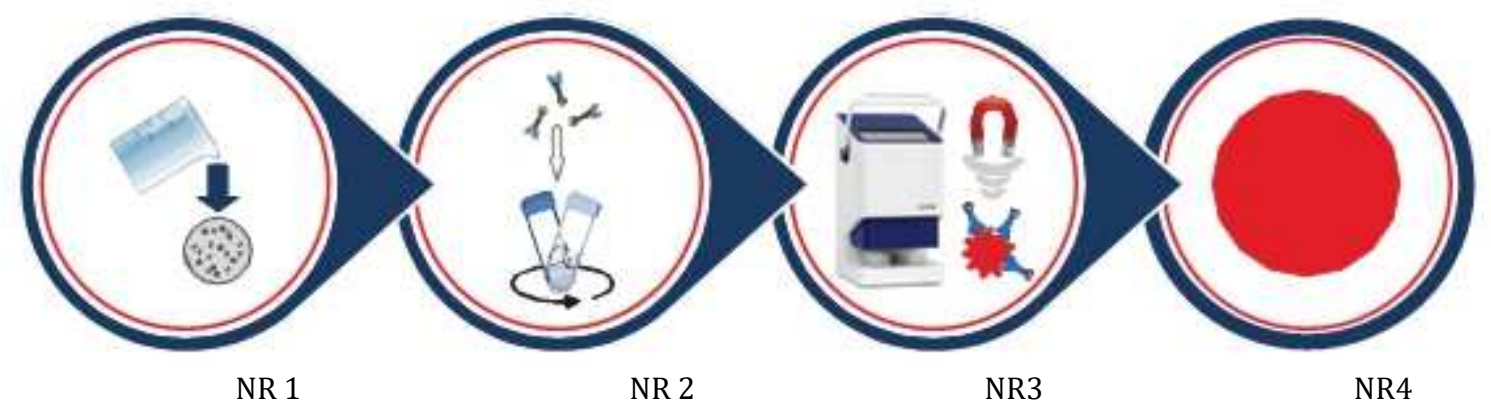

Fig. 2 Graphical presentation of individual stages of water sample analysis for the presence of Legionella pneumophilia using IMS\&FCM method.

L. pneumophila SG1 kit consists of the following components. Magnetic particles

IgG fraction anti- L. pneumophila antibodies

\begin{tabular}{ll}
\hline Membrane integrity indicator & Propidine iodide \\
\hline $\begin{array}{l}\text { Positive control - freeze-dried Legionella } \\
\text { pneumophila SG1cells (Philadelphia) }\end{array}$ & Freeze-dried \\
\hline Filters & Polycarbonate pore diameter $0.22 \mu \mathrm{m} ; \mathrm{R}-47 \mathrm{~mm}$ \\
\hline Buffer 1 & Incubation buffer \\
\hline Buffer 2 & Separation buffer \\
\hline Cartridge & $16 \mathrm{tw}$ \\
\hline Tubes & $5 \mathrm{~mL}$ \\
\hline Filters for water sample pre-filtration & Polycarbonate pore diameter $5 \mu \mathrm{m}$ \\
\hline
\end{tabular}


Validation data of L. pneumophila SG1 (Rqmicro) confirming the absence of cross-reactions with strains of high phylogenetic homology and other species of bacteria frequently occurring in water samples.

\begin{tabular}{lll}
\hline Legionella anisa & Legionella jamestowniensis & Legionella oakridgiensis \\
\hline Legionella birminghamensis & Legionella jordanis & Legionella parisiensis \\
\hline Legionella bozemanii & Legionella londoniensis & Legionella rubilucens \\
\hline Legionella cincinnatiensis & Legionella longbeachae & Legionella taurinensis \\
\hline Legionella dumoffii & Legionella micdadei & Pseudomonas aeruginosa \\
\hline Pseudomonas fluorescens & Staphylococcus aureus & Staphylococcus epidermidis \\
\hline Campylobacter jejuni & Sscherichia coli & Salmonella typhimurium \\
\hline Citrobacteri gillenii & Listeria monocytogenes & welshimeri \\
\hline Listeria fleishmanii & & \\
\hline
\end{tabular}

Validation data of L. pneumophila SG1 (Rqmicro) confirming the high specificity of the assay with respect to Legionella pneumophila strains.

\begin{tabular}{|c|c|c|}
\hline Strain & Ref. no. & Analysis result \\
\hline Legionella pneumophila Philadelphia & DSM7513 & + \\
\hline Legionella pneumophila Allentown & ATCC43106 & + \\
\hline Legionella pneumophila Bellingham & DSM25214 & + \\
\hline Legionella pneumophila Benidorm & DSM25199 & + \\
\hline Legionella pneumophila Benidorm & DSM27564 & + \\
\hline Legionella pneumophila Cambridge-1 & NCTC11231 & + \\
\hline Legionella pneumophila Camperdown & ATCC43113 & + \\
\hline Legionella pneumophila France & ATCC43112 & + \\
\hline Legionella pneumophila Heysham & ATCC43107 & + \\
\hline Legionella pneumophila Knoxville & DSM25070 & + \\
\hline Legionella pneumophila OLDA & DSM25200 & + \\
\hline Legionella pneumophila Oxford & DSM25213 & + \\
\hline Legionella pneumophila Philadelphia-2 & NCTC11193 & + \\
\hline Legionella pneumophila Pontiac & NCTC11191 & + \\
\hline Legionella pneumophila Washington & NCTC11201 & + \\
\hline
\end{tabular}

IMS immunoseparation was performed with L. pneumophila SG1 and CellStream (Rqmicro) apparatus. The choice between manual and automatic methods was dictated by the reduction of accidental contamination of the tested samples in the case of the manual method. Moreover, using the CellStream apparatus, a high repeatability of the tests was obtained, which significantly affects the reliability of the method. An additional advantage is the very short process time $<2$ hours, which does not require the user's attention. 


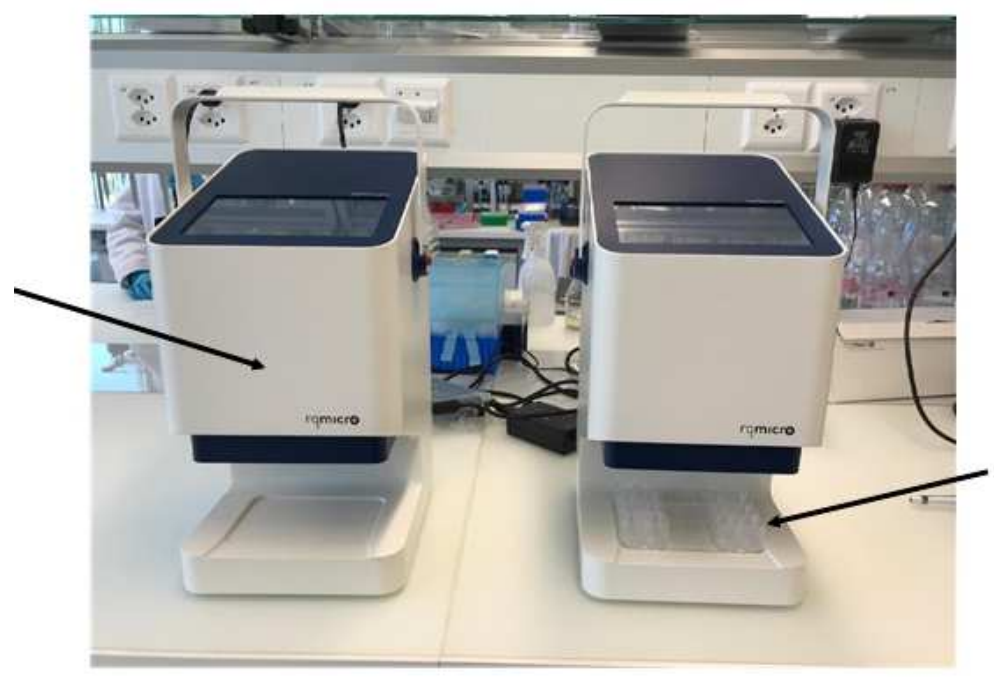

Fig. 3 CellStream devices used for testing water samples. The arrow on the left points to the magnetic immunoseparator. The arrow on the right indicates CellStream cartridge.

\section{MATERIALS REQUIRED FOR THE IMPLEMENTATION OF THE L. PNEUMOPHILA TEST METHODOLOGY}

- $\quad$ Legionella kit (rqmicro) SG1 L. pneumophila

- CellStream instrument (automatic device use in immunoseparation technique IMS)

- Flow cytometer $(488 \mathrm{~nm}$ laser - 2 detection channels Dy490 and PI, eg. Cytoflex Beckman

- $\quad$ Coulter, 525/40BP I 690/50 BP)

- Vortex

- Carousel-type mixer

- $\quad$ Pipettes with the volumes of $1000 \mathrm{ul} / 200 \mathrm{ul} / 20$ ul

- $\quad$ Eppendorf test tubes with the volume of $1.5 \mathrm{ml}$

- Stand for Eppendorf test tubes

- Falcon test tubes $50 \mathrm{ml}$

- Stand for falcon test tubes $50 \mathrm{ml}$

- Falcon test tubes $15 \mathrm{ml}$

- $\quad$ Stand for falcon test tubes $15 \mathrm{ml}$

- Tweezers

- Gloves

- Tissues

- $70 \%$ ethanol water solution
- Scissors

- Adhesive tape

- $\quad$ Fine-tip felt pen (indelible)

- Protective apron

- $\quad$ Bags for biological waste

- Timer

- Aluminium foil

The following analyses were carried out:

- Detection of positive control in the L. pneumophila SG1 process by IMS immunoseparation with analysis on flow cytometer (FCM).

Chemically inactivated strain L.p.SG1 (A). Living cells will only be present in the L.p.SG1 window after the application of the discriminatory dye (B). Axis ( $\mathrm{x}$ ) - fluorescence in the green range, axis (y) - fluorescence in the red range. 5.5x104 total L. pneumophila.

- Detection of L. pneumophila from water sample in SG1 process by IMS immunoseparation with analysis on flow cytometer (FCM).
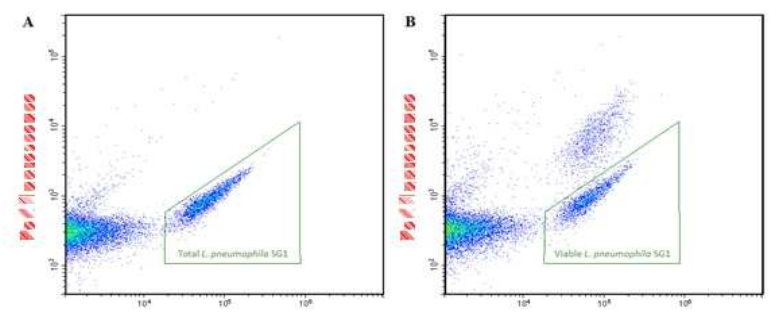

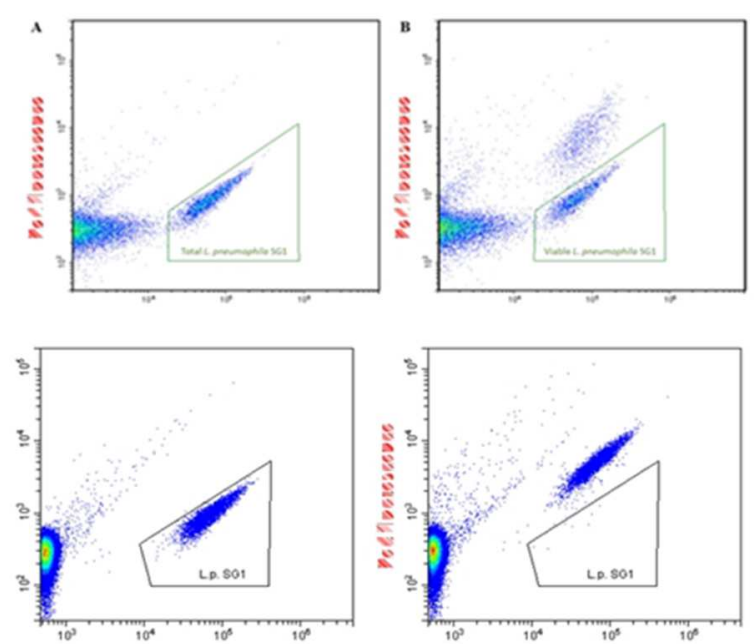

Fig. 4 Sample of tap water L.p. SG1 (A). The fraction of dead cells that was transferred out of the window after the preparation was stained with the discriminating dye (B). Live cells can only be observed in the window. Axis $(x)$ - fluorescence in the green range, axis $(y)$ - fluorescence in the red range. $4 \times 10^{4}$ total L. pneumophila in A. $2.8 \times 10^{4}$ living cells $L$. pneumophila in B.

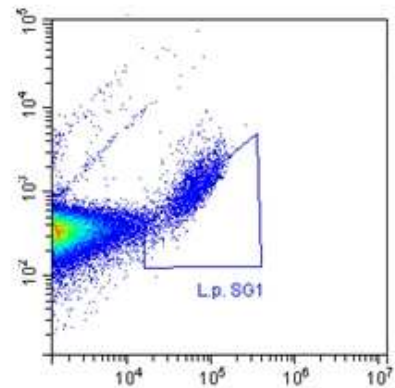

$\operatorname{Czas}(\mathrm{t})=0$ godz.

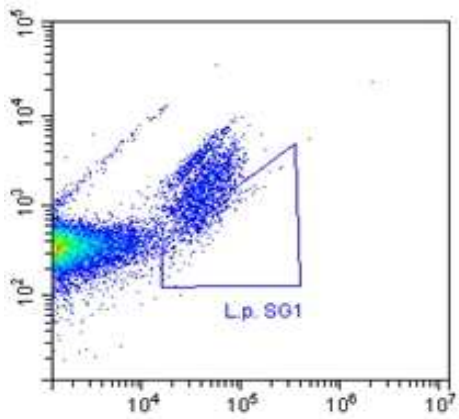

Time $(\mathrm{t})=2$ hours

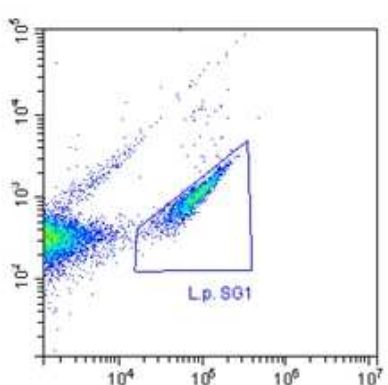

Czas $(\mathrm{t})=1 \operatorname{godz}$

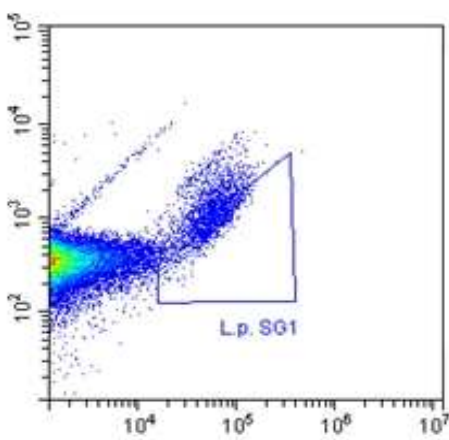

Time $(\mathrm{t})-3$ hours

Fig. 5 Detection of L. pneumophila by SG1 immunoseparation with flow cytometry (FCM) after temperature inactivation at $70^{\circ} \mathrm{C}$. After 3 hours $85 \%$ inactivation of the detected L. pneumophila strain was observed. Axis $(x)$ - fluorescence in the green range, axis (y) - fluorescence in the red range.

\section{RESULTS OF ANALYSES}

The studies were based on water samples taken in September 2018 from selected Polish Navy units located in the Naval Port of Gdynia. Volume of each sample: $200 \mathrm{ml}$. 
Sample No 1
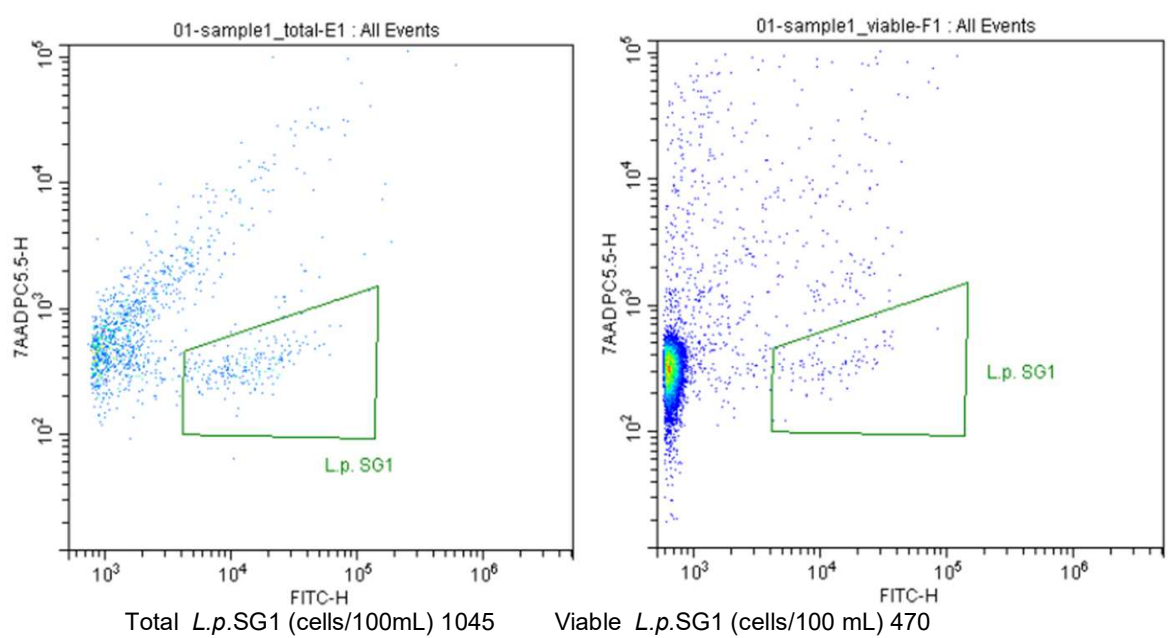

Sample No 2

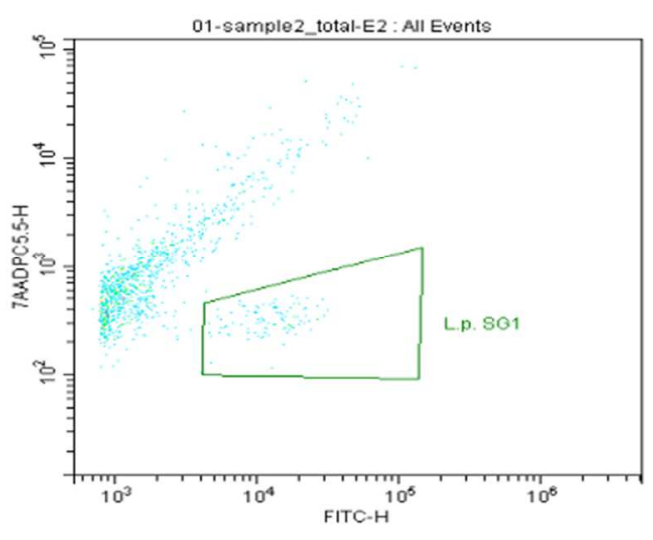

Total L.p.SG1 (cells/100mL) 505

Sample No 3

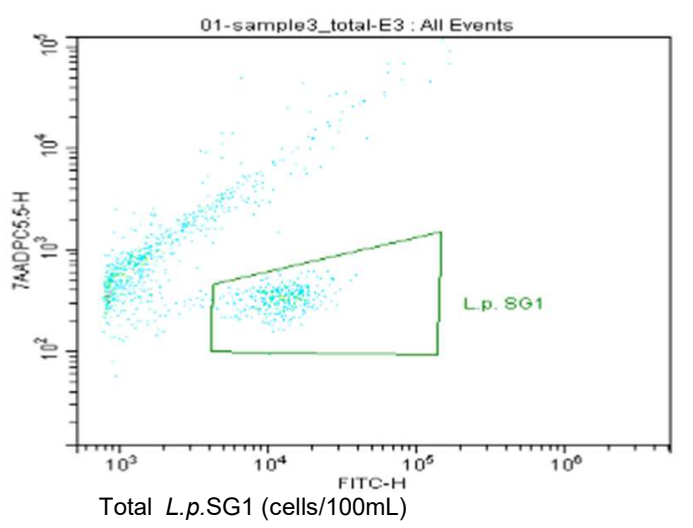

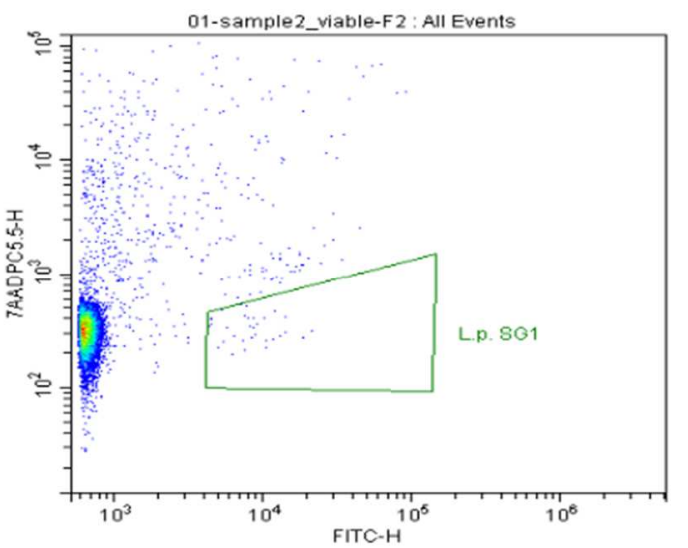

Viable L.p.SG1 (cells/100 mL) 160

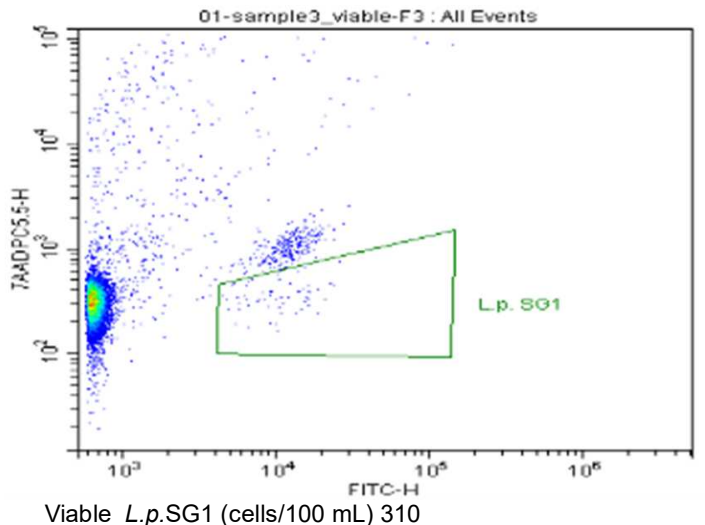


Sample No 4

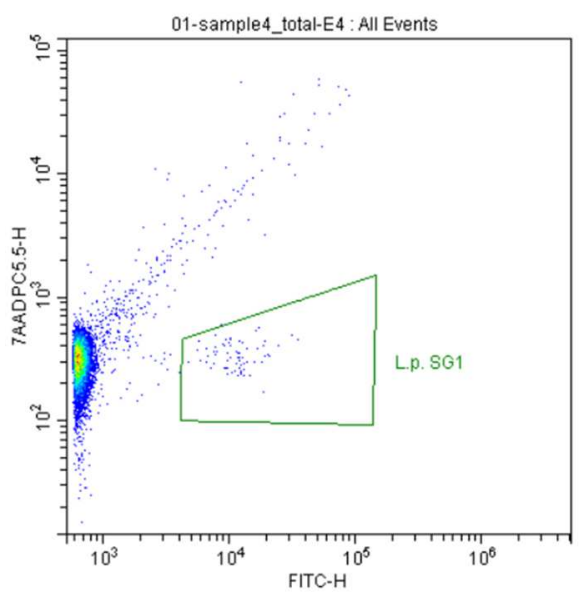

Total L.p.SG1 (cells $/ 100 \mathrm{~mL}) 335$

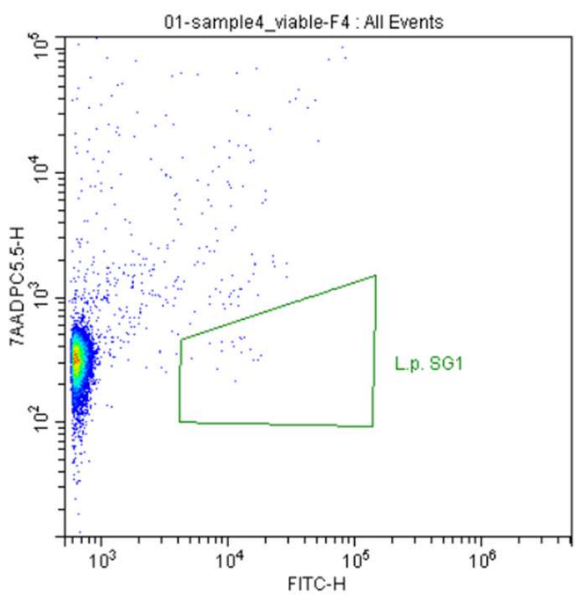

Viable L.p.SG1 (cells $/ 100 \mathrm{~mL}) 85$

Sample No 5

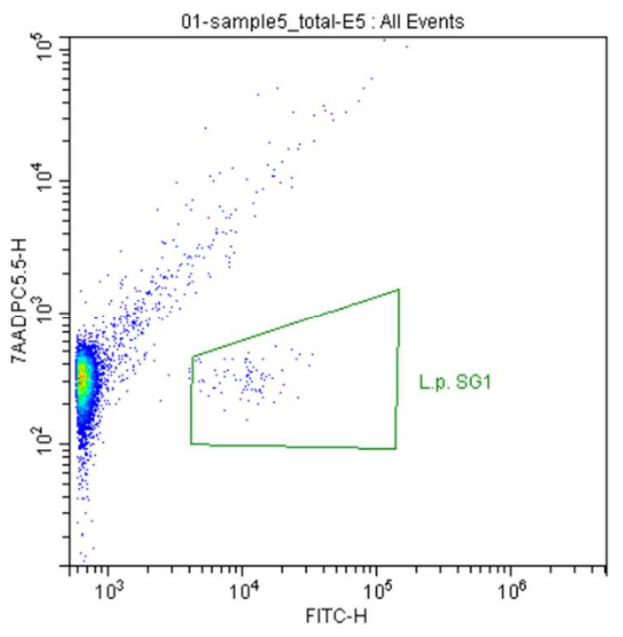

Total L.p.SG1 (cells/100mL) 385

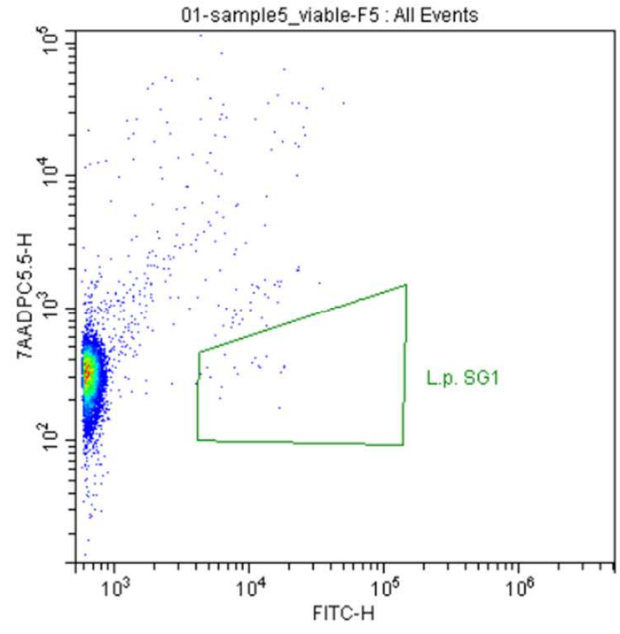

Viable L.p.SG1 (cells/100 mL) 90

Sample No 6

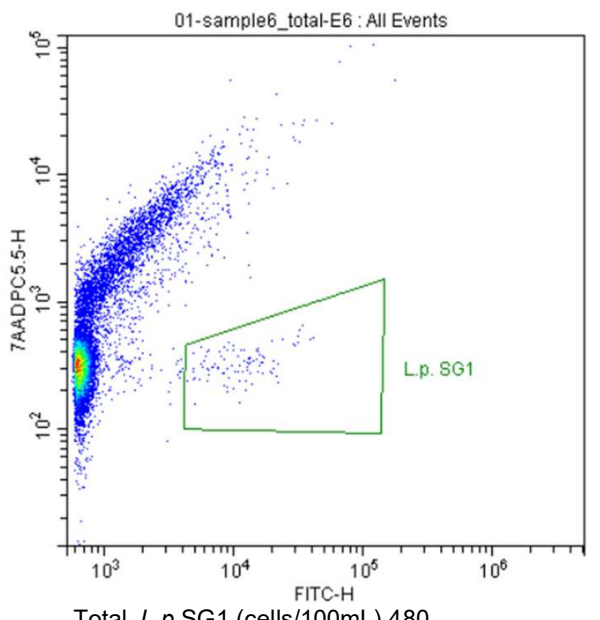

Total L.p.SG1 (cells $/ 100 \mathrm{~mL}) 480$

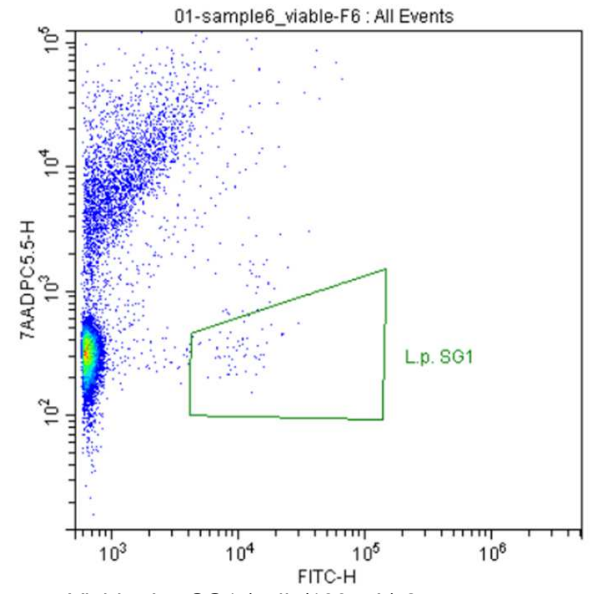

Viable L.p.SG1 (cells $/ 100 \mathrm{~mL}$ ) 275 
Sample No 7

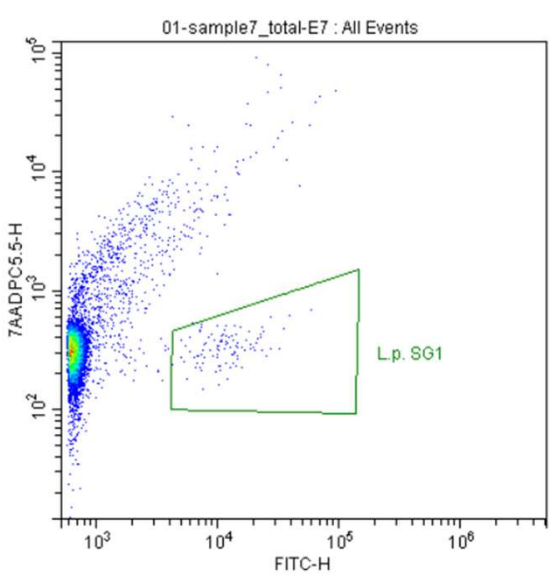

Total L.p.SG1 (cells/100mL) 520

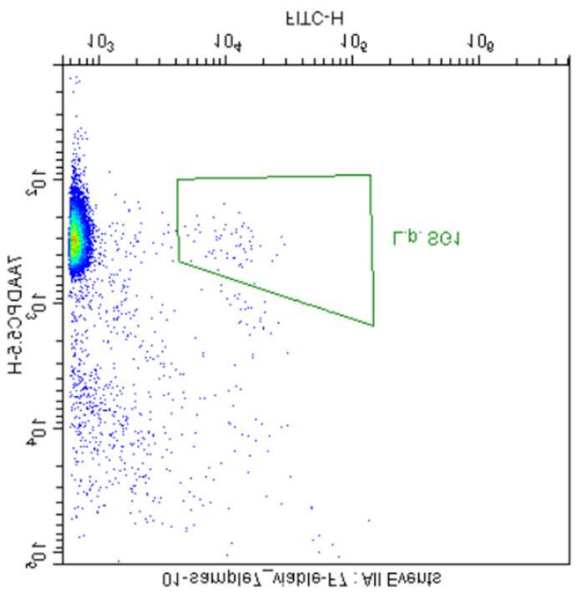

Viable L.p.SG1 (cells/100 mL) 290

\section{Sample No 8}

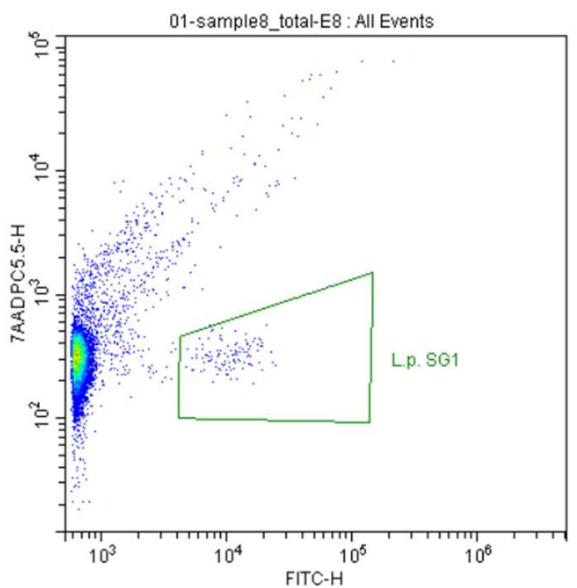

Total L.p.SG1 (cells/100mL) 545

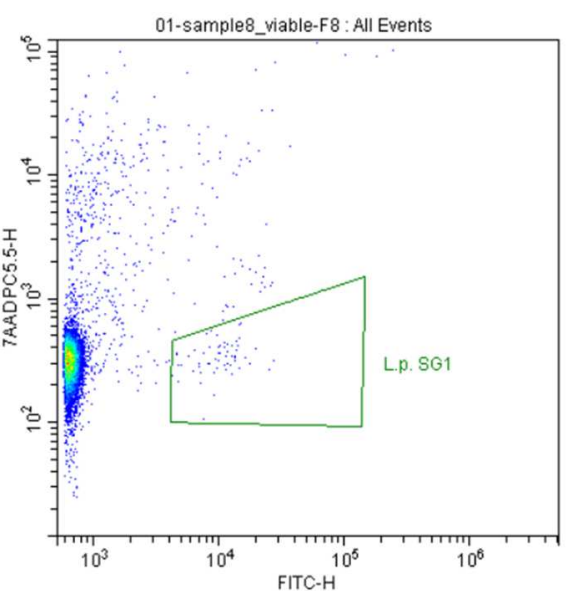

Viable L.p.SG1 (cells/100 mL) 295

\section{Sample No 9}

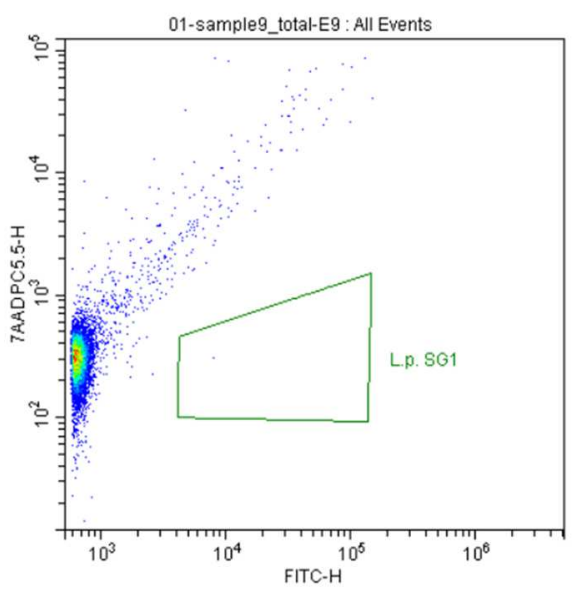

Total L.p.SG1 (cells/100mL) 0

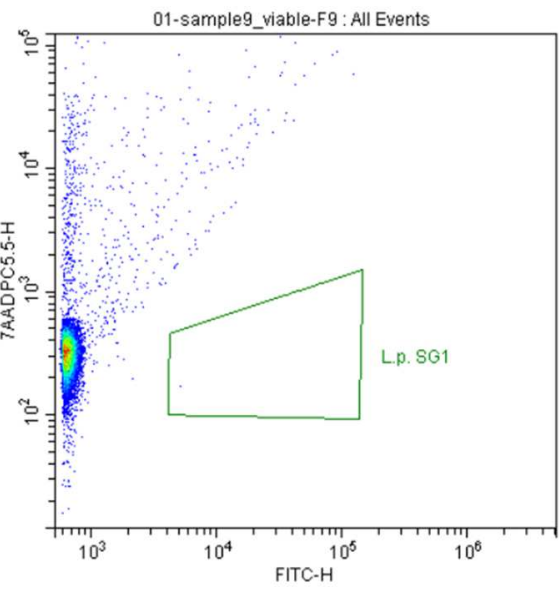

Viable L.p.SG1 (cells/100 mL) 0 
Sample No 10

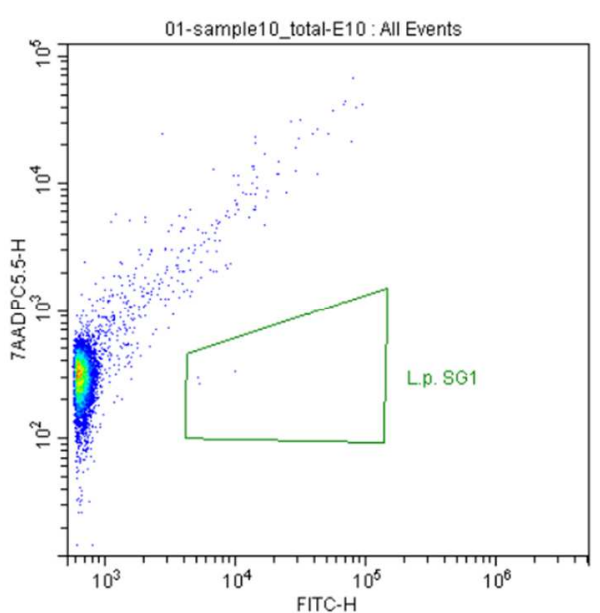

Total L.p.SG1 (cells/100mL) 0

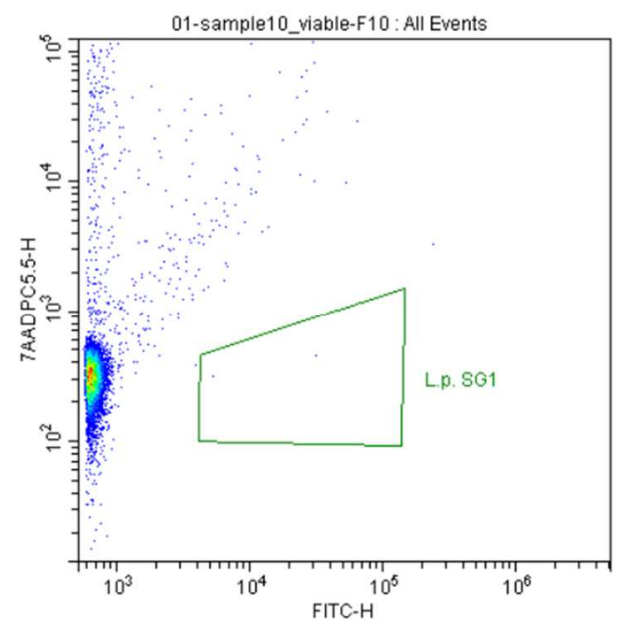

Viable L.p.SG1 (cells/100 mL) 0

Sample No 11

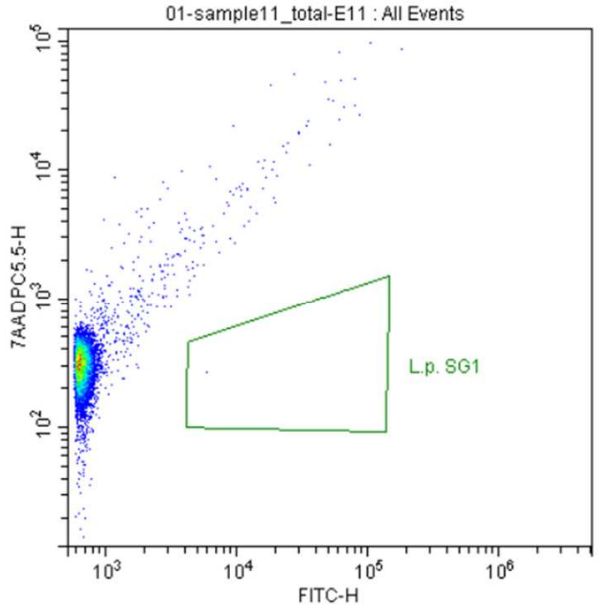

Total L.p.SG1 (cells $/ 100 \mathrm{~mL}) 0$

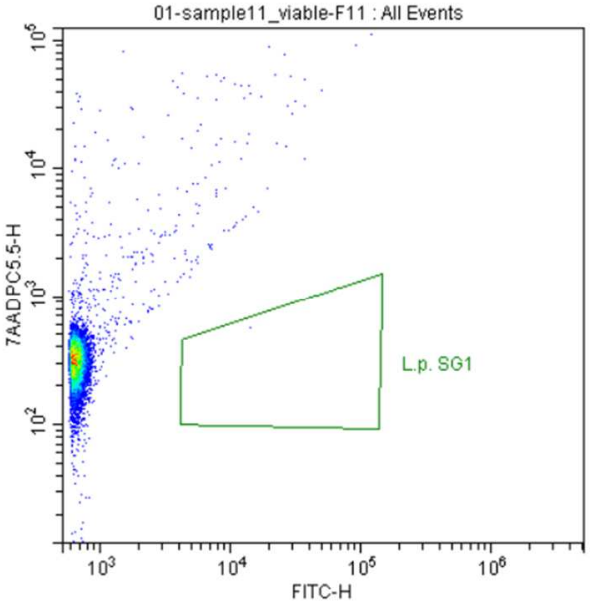

Viable L.p.SG1 (cells/100 mL) 0

Sample No 12

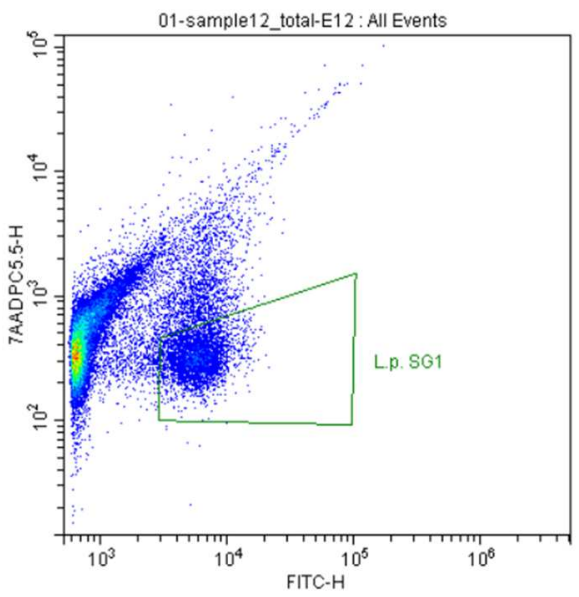

Total L.p.SG1 (cells/100mL) 20565 20'565

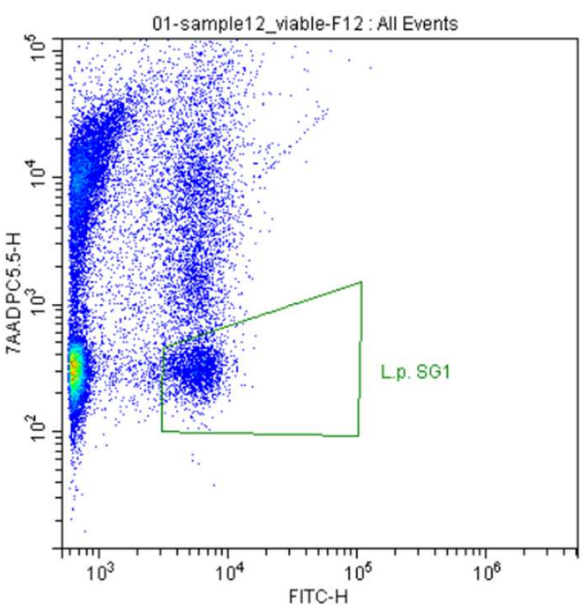

Viable L.p.SG1 (cells/100 mL) 9645 9'64565 
Sample No 13

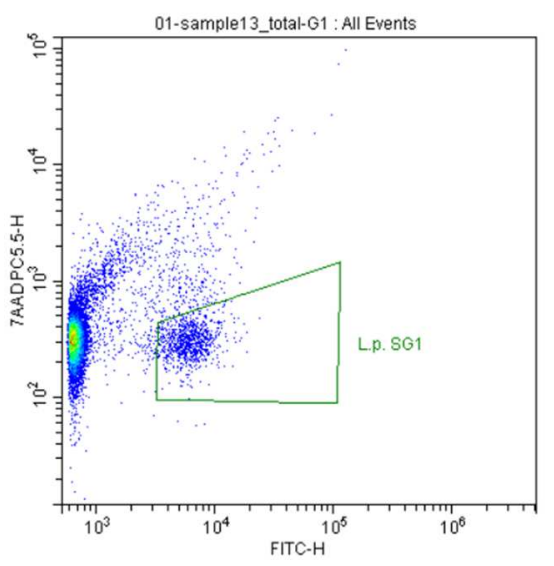

Total L.p.SG1 (cells/100mL) 4995 4'99520'565

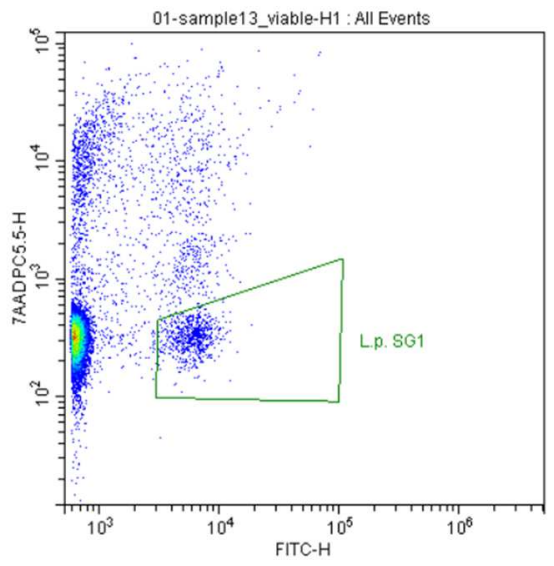

Viable L.p.SG1 (cells/100 mL) 3600 3'6009'64565

Sample No 14
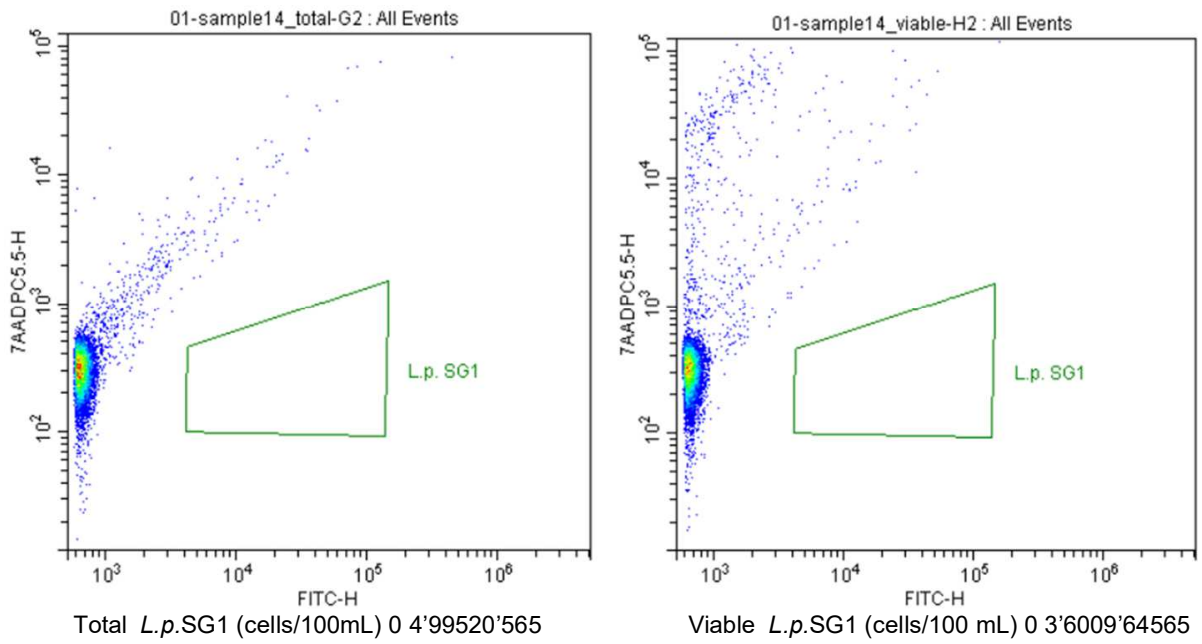

Sample No 15

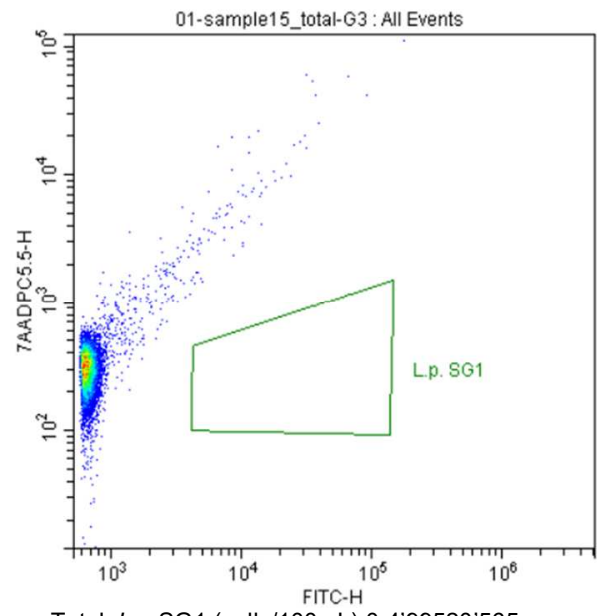

Total L.p.SG1 (cells/100mL) 0 4'99520'565

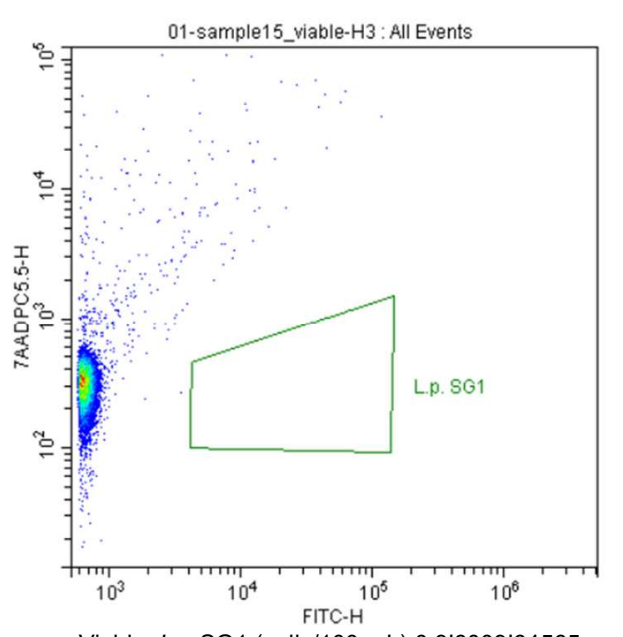

Viable L.p.SG1 (cells/100 mL) 0 3'6009'64565 
Sample No 16

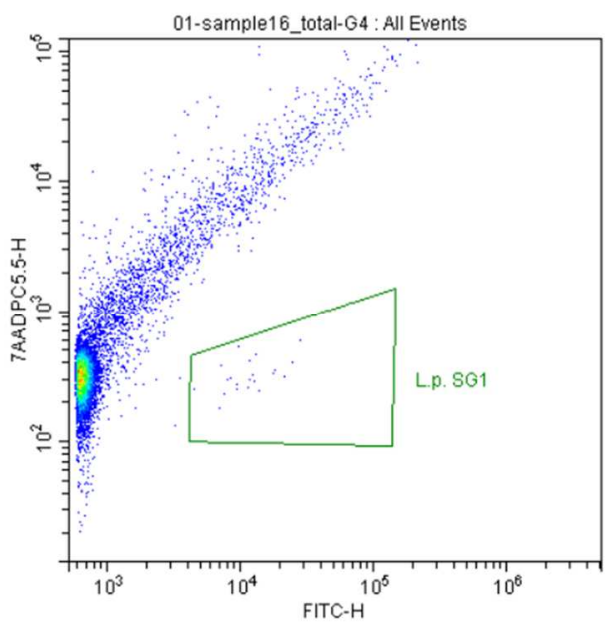

Total L.p.SG1 (cells/100mL) 165 4'99520'565

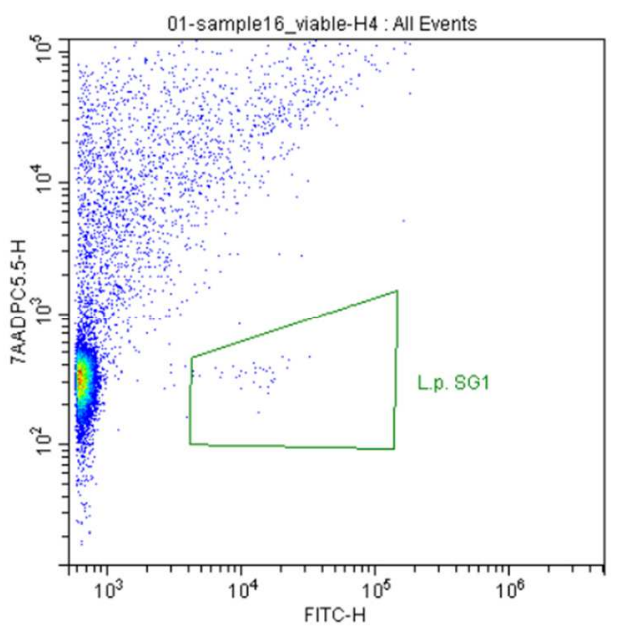

Viable L.p.SG1 (cells/100 mL) 110

Sample No 17
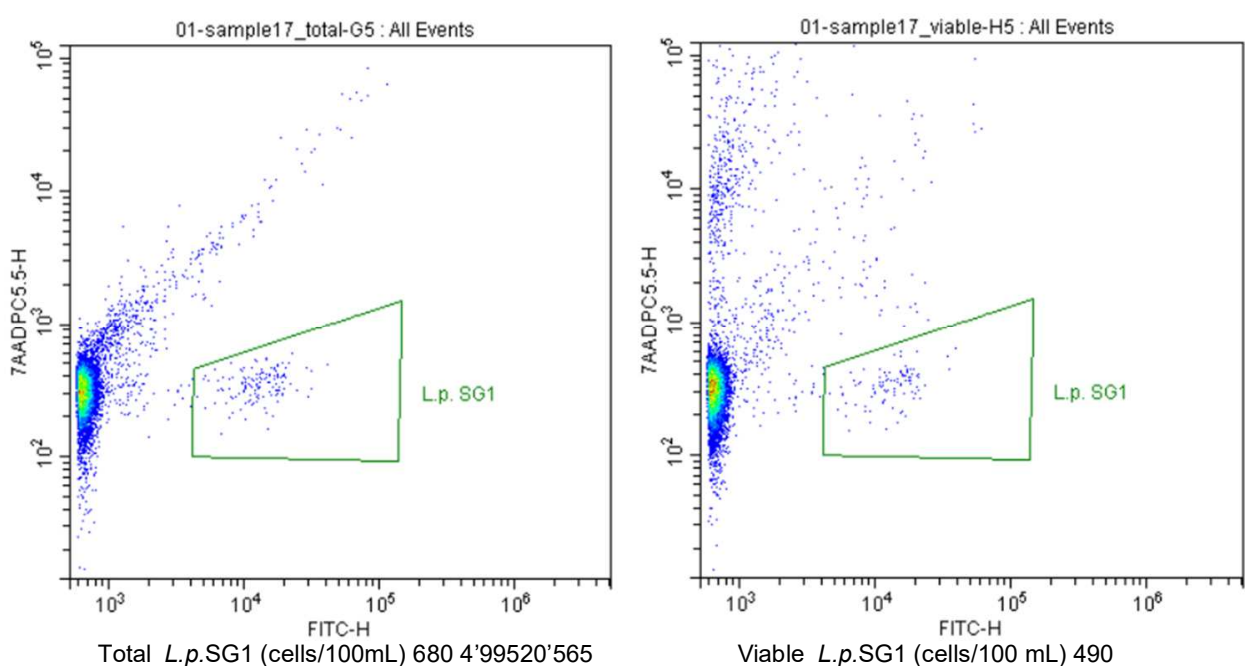

Sample No 18
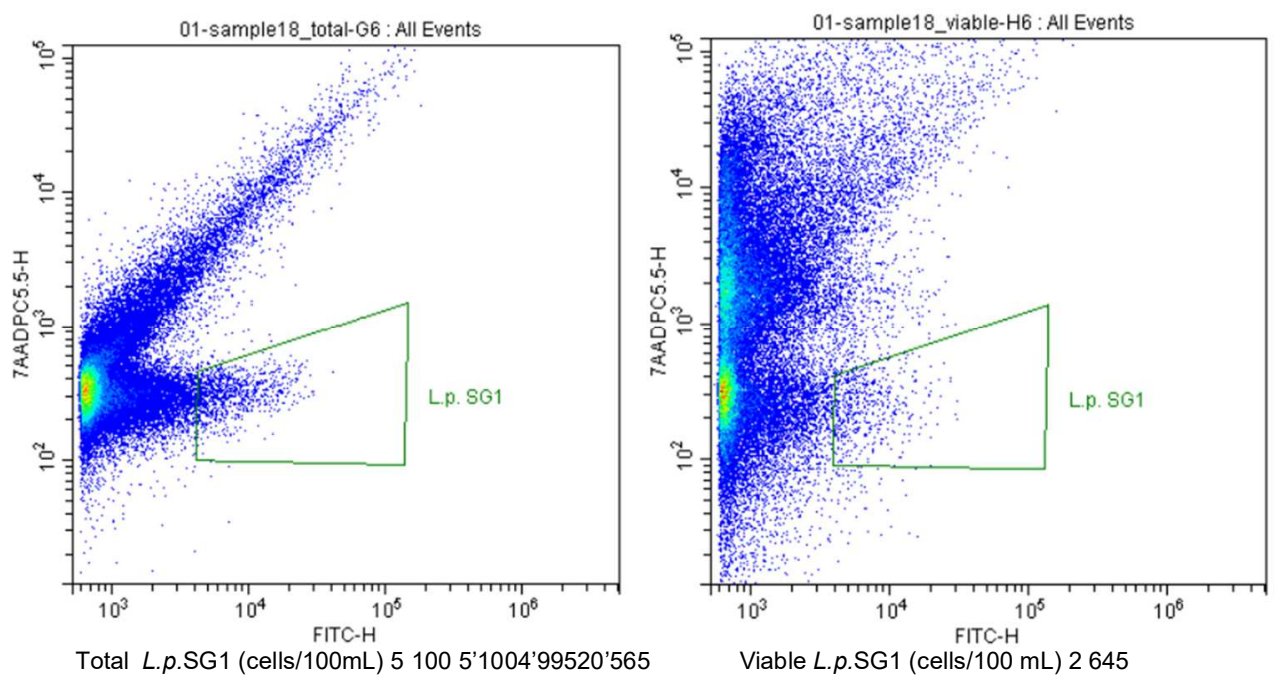

Total L.p.SG1 (cells/100mL) 5100 5'1004'99520'565 
Sample No 19

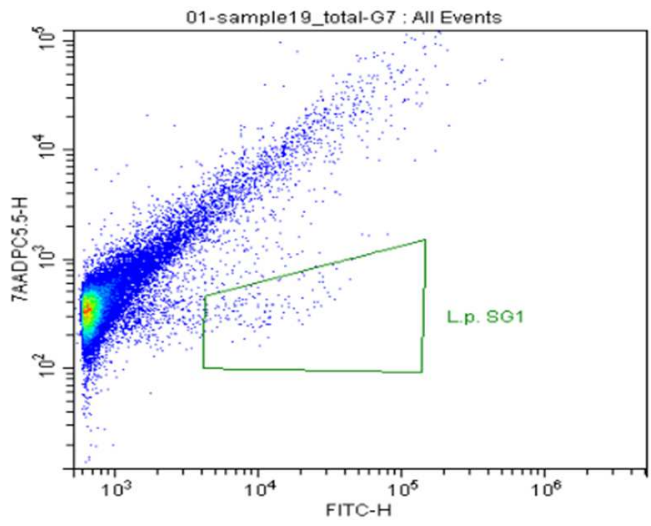

Total L.p.SG1 (cells/100mL) 635 5'1004'99520'565

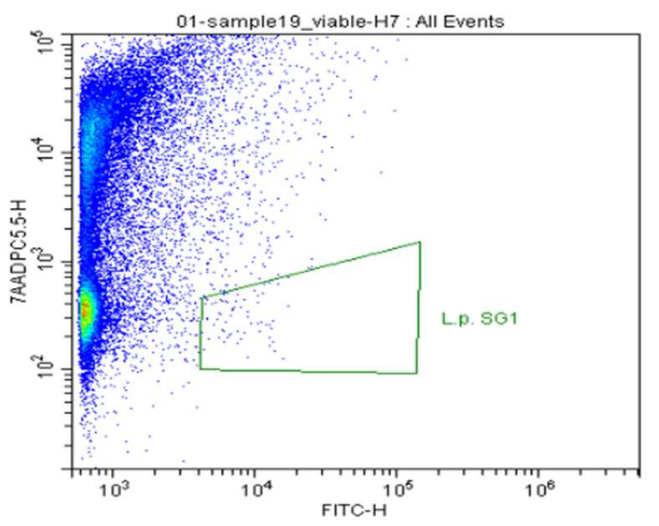

Viable L.p.SG1 (cells/100 mL) 345

Summary of the results of the $L$. pneumophila test on the water samples obtained.

Sample no. Type of analysis Total count wg

\begin{tabular}{|c|c|c|c|c|c|}
\hline & & & & & $\mathrm{qPCR} / 100 \mathrm{~mL}$ \\
\hline 1 & L.p. SG1 & 1’045 & 470 & $45.0 \%$ & 8400 \\
\hline 2 & L.p. SG1 & 505 & 160 & $31.7 \%$ & 6240 \\
\hline 3 & L.p. SG1 & $1 ‘ 785$ & 310 & $17.4 \%$ & 11200 \\
\hline 4 & L.p. SG1 & 335 & 85 & $25.4 \%$ & 5720 \\
\hline 5 & L.p. SG1 & 385 & 90 & $23.4 \%$ & 5520 \\
\hline 6 & L.p. SG1 & 480 & 275 & $57.3 \%$ & 5800 \\
\hline 7 & L.p. SG1 & 520 & 290 & $55.8 \%$ & 6400 \\
\hline 8 & L.p. SG1 & 545 & 295 & $54.1 \%$ & 6480 \\
\hline 9 & L.p. SG1 & 0 & 0 & $0.0 \%$ & 0 \\
\hline 10 & L.p. SG1 & 0 & 0 & $0.0 \%$ & 0 \\
\hline 11 & L.p. SG1 & 0 & 0 & $0.0 \%$ & 0 \\
\hline 12 & L.p. SG1 & $20 ‘ 565$ & $9 ‘ 645$ & $46.9 \%$ & 21200 \\
\hline 13 & L.p. SG1 & 4‘995 & $3 ‘ 600$ & $72.1 \%$ & 14400 \\
\hline 14 & L.p. SG1 & 0 & 0 & $0.0 \%$ & 0 \\
\hline 15 & L.p. SG1 & 0 & 0 & $0.0 \%$ & 0 \\
\hline 16 & L.p. SG1 & 165 & 110 & $66.7 \%$ & 5200 \\
\hline 17 & L.p. SG1 & 680 & 490 & $72.1 \%$ & 5600 \\
\hline 18 & L.p. SG1 & $5 ‘ 100$ & $2 ‘ 645$ & $51.9 \%$ & 14800 \\
\hline 19 & L.p. SG1 & 635 & 345 & $54.3 \%$ & 56400 \\
\hline
\end{tabular}

\section{DISCUSSION AND CONCLUSIONS}

By comparing the immunoseparation method (IMS) combined with flow cytometry (FCM) analysis with real-time PCR (qPCR), it is possible to draw the following conclusions:

- The (IMS \& FCM) method is the closest to the classical method considered as the standard for the determination of Legionella spp. according to the standard no. PN-EN ISO 19457:2007 I PN ISO 11731:2002.

- The method (IMS \& FCM) allows a clear distinction to be made between living and dead cells in the analysed environmental sample.

- Compared to the standard method, the procedure (IMS \& FCM) may be performed within 2 hours of the arrival of the samples at the laboratory. The method has a high degree of automation in sample determination, allowing dozens of environmental sample determinations to be performed in one day.

- High throughput of the method results in a radical reduction of costs of Legionella spp. determination in environmental samples. According to the prices of Legionella spp. determination in 2018 the average cost of one sample is 300 PLN. The method (IMS \& FCM) allows to reduce the cost of determination to 86 PLN per one sample.

- In the case of qPCR method, the time of Legionella determination in environmental samples is comparable to the (IMS \& FCM) method, but there are significant difficulties in interpreting the results consisting in:

$\checkmark \quad$ the necessity of each calibration of the results based on the curve of dependencies between colony-forming units (cfu) and genomic units (gu), 
$\checkmark$ the results obtained with the qPCR method concern both the genetic material from dead and living Legionella spp. cells, which may make it difficult to determine the extent of the reparative measures taken when Legionella spp. levels above $100 \mathrm{cfu} / 100 \mathrm{ml}$ are found in samples of collected water.

In the event of an epidemic of Legionnaires' disease, a prompt and unambiguous determination of the source of infection and immediate undertaking of remedial actions is a necessary condition for limiting and minimising the effects of the developing epidemic.

The guidelines of the National Hygiene Institute regarding the level of Legionella bacteria in the tested water, contained in the 2001 study on Methodology for Detection and Labelling of Legionella Bacteria in the Aquatic Environment and Clinical Material, are as follows:

- $\quad<10^{3}$ bacterial cells of the genus Legionella in 1 litre of water - a properly operated system.

- $\quad 10^{3}-10^{4}$ bacterial cells of the genus Legionella in 1 litre of water - warning level, it is required to repeat the test.
- $\quad>10^{4}$ Legionella bacterial cells in 1 litre of water - repeat the test and simultaneously undertake intervention activities including cleaning and disinfection of the system.

- If the presence of Legionella pneumophila is detected, it is necessary at all times to carry out cleaning and disinfection of the system

According to the National Institute of Hygiene, water should be tested in public utility buildings (sanatoriums, hospitals, social welfare homes), hotels and large residential complexes, and in cooling water systems at least twice a year [7].

In the classic method of determining the level of Legionella in water samples, the effectiveness of the reparative action (increasing the temperature of water in the water supply system to $60^{\circ} \mathrm{C}$ plus additional chlorination) can be confirmed only after 14 days!!!

Only the IMMS \& FCM method shortens the time of Legionella determination to 2-4 hours, which is the most important factor limiting the development of the epidemic.

\section{REFERENCES}

1. Windscreen wiper fluid without added screenwash in motor vehicles: a newly identified risk factor for legionnaires' disease., Anders Wallensten et al , Eur.J.Epidemiol(2010);

2. PN-EN ISO 19458 2007: Water quality - Taking samples for analysis;

3. PN-ISO 1131:2002: Water quality - Detection and quantification of Legionella spp. PKN 2002;

4. PN-EN ISO $11731-2: 2008$ Water quality. Detection and quantification of Legionella spp - Part 2: Methodology for membrane filtration in waters with low bacterial count PKN 2008;

5. Yuhe Wang, Qi Chen, Chegqi Gan, Bo Yan, Yaguan Han, Jiahan Lin (2016) A Review on Magnetophoretic Immunoseparation, J.Nanosci. Nanotechnol 16, 3, 2152-2163;

6. Łukasz Sędek, Alicja Sonsala, Tomasz Szczepański, Bogdan Mazur (2010) The technical aspects of flow cytometry, Diagnostyka laboratoryjna 46,4,415-420;

7. Andrei Shpakou, Iwona Gładysz, Agnieszka Sikora, Małgorzata Wójtowicz-Bobin, Maria Kozioł-Montewka (2017), The occurrence of Legionella spp. bacteria in selected public utility facilities in Poland in the years 2009-2013, Health problems of Civilization, 11,2,117-123.

dr n. biol. Zbigniew Dabrowiecki

Zakład Medycyny Morskiej i Hiperbarycznej

Wojskowy Instytut Medyczny

ul. Grudzińskiego 4 81-103 Gdynia 3 skr. poczt. 18

tel: 604291581

e-mail: zdabrowiecki@wim.mil.pl 